\title{
SOLAR TECHNOLOGIES APPLICATION IN MILK PRODUCTION
}

\author{
Andrejs Snegirjovs, Kristina Lebedeva, Galina Kashkarova, Peteris Shipkovs \\ Institute of Physical Energetics, Latvia \\ shipkovs@edi.lv
}

\begin{abstract}
The main directions of efficient, balanced market-based energy policy of Latvia are set out in the informative report "Long-Term Energy Strategy 2030 - Competitive Energy for the Society", one of the main objectives of the strategy being to ensure a positive impact of the energy sector on the Latvian economy sustainable energy, it means to reduce dependence on energy imports, to promote new, efficient technologies for the use of renewable energy and carrying out of energy efficiency improvement measures. It is fully in compliance with the operational strategy of the Ministry of Agriculture of the Republic of Latvia for 2017-2019 and related to the EU's progress towards the development of the bioeconomy as a crucial element in the challenges of today's global change. Resource depletion and increasing impact on the environment greatly increase the demand for food as well as competition for resources, including agricultural land. Regarding the development of sustainable agricultural development, it is necessary to prepare a platform for the development of bioeconomy, taking into account related policies and their objectives, integrating bioeconomic principles in order to ensure the production of high added value products, to promote scientific and business synergies and innovations in production, create well-paid jobs in rural areas, reducing dependence on fossil resources, sustainable use of renewable resources, by preserving of biodiversity and climate change mitigation. Rational energy efficiency increasing in agriculture is the main way to self-sufficiency. Nowadays, there is high potential of renewable energy source applications in different processes of the agriculture sector. Energy demand extrema in milk production is close to solar radiation extrema. This opens wide opportunities of solar technology application. Deep analysis shows that there exists a gap in solar radiation peak and electricity demand peak. It means that energy accumulation is needed for higher performance. The publication describes comparison of different solar energy accumulation type application in the milk production sector. Comparisons include pros and cons of electrical and thermal solar energy accumulation.
\end{abstract}

Keywords: solar energy, photovoltaic (PV), electricity accumulation.

\section{Introduction}

Renewable energy and farming are a winning combination. Wind, solar, and biomass energy can be harvested forever, providing farmers with a long-term source of income. Renewable energy can be used on the farm to replace other fuels or sold as a "cash crop" [1].

The amount of energy from the sun that reaches the Earth each day is enormous. All the energy stored in the Earth's reserves of coal, oil, and natural gas is equal to the energy from only 20 days of sunshine.

Photovoltaics (solar electric panels) can power farm operations and remote water pumps, lights, and electric fences. Buildings and barns can be renovated to capture natural daylight, instead of using electric lights. Solar power is often less expensive than extending power lines.

The typical mid-sized dairy farm uses a large amount of energy during milking activities. This is due to the frequency of milking and the energy intensive nature of harvesting milk, keeping it cool, and cleaning the equipment with hot water. Renewable energy systems generally become more economically efficient as the amount of energy used increases, making dairy farms a great place to incorporate renewable energy [2-4].

Dairy farms have not typically been set up with energy efficiency in mind and often use relatively expensive fuel sources like heating oil or propane to heat water. One of the difficulties encountered with renewable energy systems is the intermittent generation of wind and solar energy, whereas the energy load on a dairy farm is very consistent, since cows are typically milked twice or three times every day (very large dairies may milk continuously) [6]. An efficient way to store energy has long been sought to tie energy production and consumption together. A dairy farm's need for both electricity and heat provides an ideal situation to generate electrical energy on-site to meet the current electrical load requirements, displace conventional thermal fuels with electrical energy, and evaluate thermal storage as a solution to the time shifting of wind and solar electrical generation. 


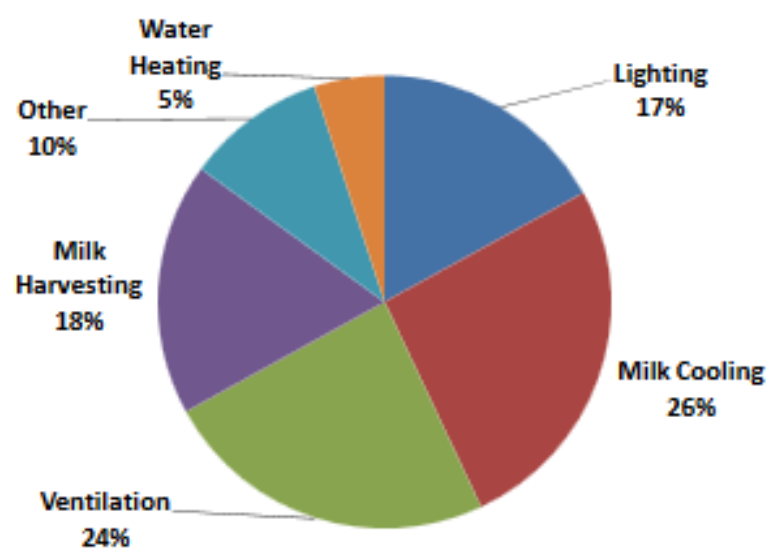

Fig. 1. Dairy farm energy consumption [5]

\section{Materials and methods}

The paper is based on PV tests, field research, and dairy farming monitoring on side.

Photovoltaic system experiments and tests were done at the "Solar energy testing polygon" that is located at the Institute of Physical Energetics in Latvia. The testing polygon has six PV arrays with nominal power from 1.5 till $4 \mathrm{~kW}$. Each array has independent Maximum Power Point Tracking (MPPT), because of different technology of PV modules and different tilt angles. It should be noted that PV tracking technologies are not included in this study. PV electricity generation yield is measured with tolerance at least $1 \mathrm{~W}$ at DC and AC sides. Data of PV yield under real weather conditions are collected for more than 10 years.

Electricity consumption for milk production is based on real data from dairy farming in Latvia. It was detected that small and medium size dairy farms have the highest potential for energy consumption reducing per yield. Therefore, the farms with milk production till $100 \mathrm{~m}^{3} /$ year were included in the study. Energy consumption of thelast 3 years withthe time step 1 month was received from 8 milk producers.

\section{Result and discussion}

The main objective of this publication is to analyze the possibility of rational use of solar panels on dairy farms. Electricity generated by solar batteries can be used for power supply: vacuum machines and transfer pumps; milk coolers; ventilation; hot water heating and for farm cleaning systems.

The study includes merely mass-used technologies of solar cell systems. Innovative PV technologies of the last year are not included in the calculation, as the prices for the components of these units are high and their practical effectiveness is not sufficiently tested in real conditions.

The volumes of milk produced are cyclical with peaks of solar radiation in the spring-summer period of the year. The highest amount of solar radiation also falls on summer time. By breaking energy consumption into components, the variation in daily and annual energy consumption becomes more understandable.

Correlation of energy consumption of dairy farms and generation of electricity by solar batteries in the Baltic region has not been described in widely available scientific sources of information.

The deviations of daily energy consumption is a primarily result from milking of cows by vacuum milking and subsequent sterilization, and cooling of milk. In smaller farms this cyclicity is more pronounced, while on large farms they try to optimize the process and evenly use the technological equipment during the day.

The process of cleaning the farm is often carried out after the morning milk yield - hence the deviation in the consumption of hot water and the subsequent heating of electric boilers takes place before the midday period. Lighting has a minimal impact on power consumption. 
Despite the fact that the technology cannot be interrupted, a slight decrease was stated in power consumption at the weekend. The explanation is that the implementation of preventive works is mainly on working days.

As it can be seen in Fig. 2, the specific power consumption for the amount of produced milk has a decrease more than 2 times in summer. This is mainly due to a multiple increase in the milk yield in summer. From what follows, the constant component of power consumption for barn maintenance is high and has a tangible potential for improving the energy efficiency of small and medium-sized dairy farms.

The basis for the seasonal variation of energy consumption is increased milking in summer and the need for heating in winter. The basis of heat supply systems for dairy farms in the Baltics is local combustion of biomass in heating boilers with installed capacity up to $30 \mathrm{~kW}$. The main heating systems are radiators, and occasionally air heating. In consequence of that, electricity consumption in the heating systems is minimal.

Energy consumption for ventilation is evenly distributed in winter. In summer, the ventilation system has a peak load at night, because during the day cows graze under open sky. Air conditioning of the cowsheds is not used due to acceptable air temperatures in the summer months in the Baltic countries.

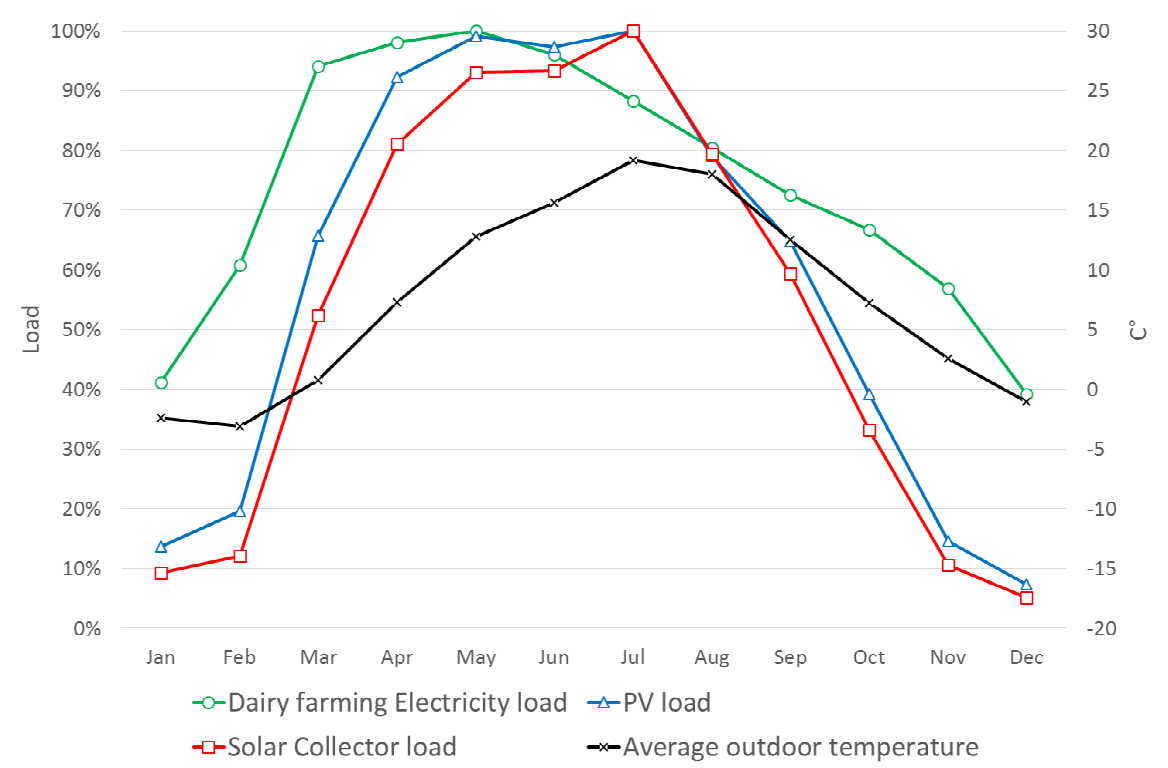

Fig. 2. Comparison of electricity consumption load at conventional dairy farming and equipment generated load

Seasonal power consumption of dairy farms and power generation of solar equipment have a similar tendency, see Fig. 2. Nevertheless, the peak load of the electric consumption of dairy farms begins with early spring. While the peak of solar cell production and solar collectors is observed during summer.

This implies that the use of solar power systems is potentially rational for dairy farms. In turn, shifts in the daily energy consumption and electricity generation show the need for a buffer of electricity. The buffer can be either a power grid with the sale and subsequent purchase of electricity, or electric accumulators.

Since a fully electro-autonomous dairy farm is not possible under the Baltic conditions, the choice between the types of buffer is more dependent on the economic component. The recommended capacity of the battery is equal to the maximum electrical generation solar cells in the sunniest day.

The technological process of dairy farms indicates that dairy farms need electricity, heat and cooling. Given the energy consumption trends, it makes sense to consider the possibility of using three-generation on a solar generator. The concept of solar triangulation, developed in cooperation of the Institute of Physical Energetics (IPE) - Latvia and the SPF Institute for Solar Technology Switzerland, can be effectively used in dairy farms, as this system has already been tested in IPE. 
This technology is based on the use of solar batteries (PV) to operate a compression machine. In the system there are two accumulators, one is for cooling, connected to an antifreeze circuit, the second for hot water supply with an aqueous circuit. The compression machine transfers heat energy from one battery to another, and also separates the contours.

Heat supply and refrigeration consumed energy from accumulator batteries as needed. And also the batteries smooth the peaks of consumption. The main advantage of this system is the similarity of the seasonal peaks of generation with the peaks of consumption.
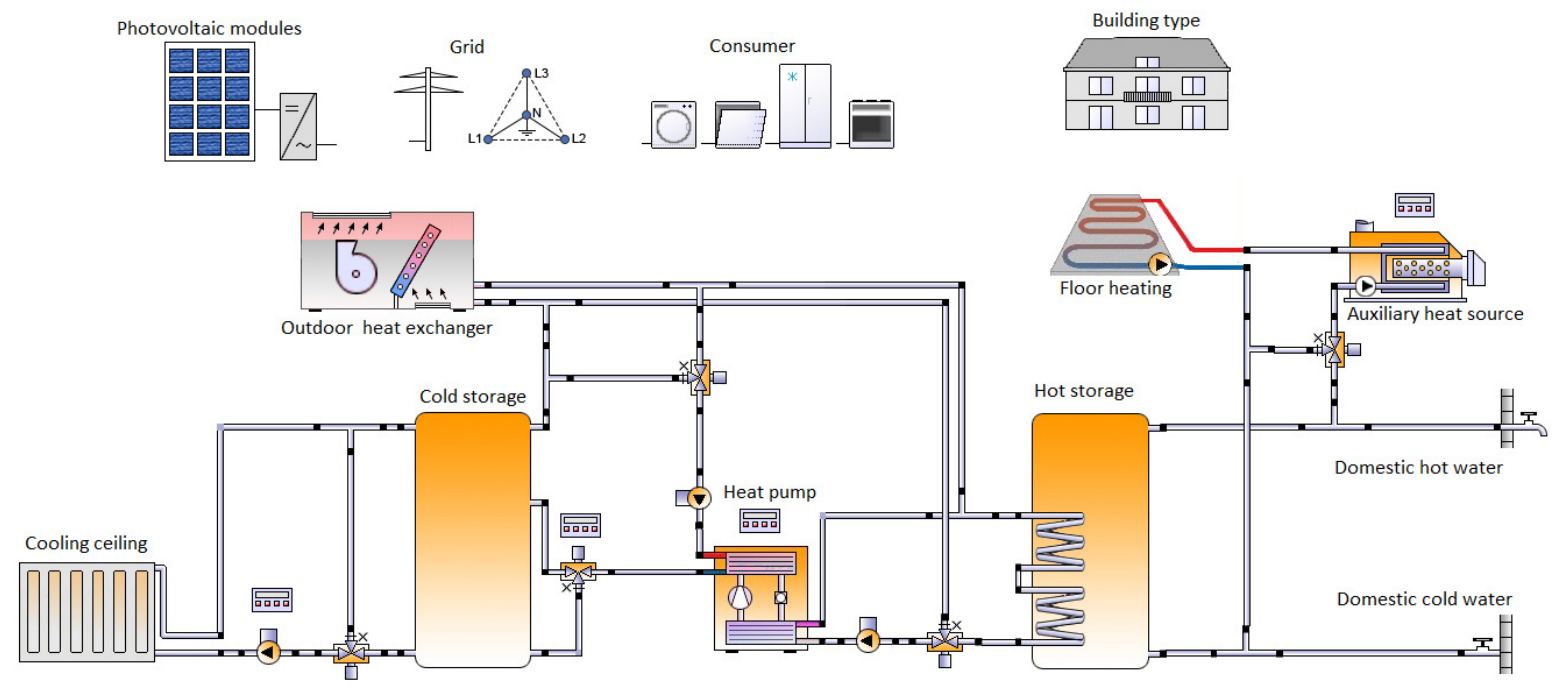

Fig. 3. Principal scheme of solar trigeneration

Initially, this technology was designed for air cooling in the living space. It is necessary noting that in the off-seasons the generated energy was at times more than the consumed, because air conditioning in the off-seasons was minimal.

However, there is a need for milk cooling even at low ambient temperatures. The development of PV systems directly stimulates the development of a compression machine and sets the reserves of cooled and heated heat carrier.

Now there is no information on the use of solar trigeneration systems in dairy farms. It is worth noting that the above described technology proves the validity of combining these two technologies. Undoubtedly, it is necessary to adjust the solar trigeneration system to the structure of dairy farms as a result of the absence of pilot examples and a rather broad description of the specifics of this combination.

Taking in account the very rapid technological progress and falling prices for modern technologies with rising prices for fossil fuels, this new technology could be used in agriculture in the near future.

\section{Conclusions}

Solar energy use becomes more and more actual in the recent years. As shown by experimental studies, the application of solar collectors in Latvia can give good results in the agriculture sector; especially solar energy should be used for hot water preparation in dairy farms, taking in account effective solar energy use, a relatively long service life - 25-30 years and low operating costs.

Solar panels are falling in price, especially in the last 15 years, when the cost of PV systems fell annually by $10 \%$ from the price for the previous year. This significantly increases the economic interest in solar energy use. Currently, there is an active search for the development of new applications of PV. The main disadvantage of solar energy is the inconsistency in the peak of energy production with peak consumption. In turn, the peak of the need for power of dairy farms is closest to the peak of solar radiation and is therefore close to the peak of the PV performance. Taking into account the coincidence of the peaks of energy production with the peak of consumption, the use of solar batteries in agriculture on dairy farms becomes especially relevant from the technological and economical points of view.

As follows from the research, the use of solar PV systems for the power supply of dairy farms is expedient, since there is a seasonal coincidence of the electrical power and PV generation graphs. The 
existing shifts in daily energy consumption and electricity generation must be leveled. The buffer can be either an electric grid with the sale and subsequent purchase of electricity, or the accumulation of energy in batteries. Due to the fact that the cost of batteries is reduced, and the period of their operation is increasing, the use of PV becomes economically and technically expedient.

\section{Reference}

[1] Masson G., Orlandi S., Rekinger M. Global Market Outlook for Photovoltaics 2014-2018. Brussels, Belgium: European Photovoltaic Industry Association, 2014, 60 p.

[2] Upton J., Humphreys J. Energy demand on dairy farms in Ireland -2013 - Journal of Dairy Science, Volume 96, Issue 10, October 2013, pp 6489-6498.

[3] Sun A., Reindl D., Reinemann D., Energy Use in Wisconsin's Dairy Industry and Options for Improved Energy Efficiency - 2011 - JAEE, SAP, Wisconsin, USA, 94 p.

[4] Upton J., Murphy M., French P. and Dillon P. Dairy farm energy consumption. in Teagasc Nation. - 2010 - Dairy Conf. Mullingar, Ireland, pp. 87-97.

[5] Pressman, A. Dairy Farm Energy Efficiency. - 2010 - National Sustainable Agriculture Information Service.

[6] Kraatz S., Energy intensity in livestock operations-modeling of dairy farming systems in Germany. - 2012 - Agric. Sys. 110, pp. 90-106. 